\title{
Feasibility of the modified 30-second sit-to-stand test in an isolation ward of moderate COVID-19
}

Evi Rachmawati Nur Hidayati, ${ }^{1}$ Amien Suharti, ${ }^{1}$ Adis Tiara Suratinoyo, ${ }^{1}$ Silma Rahima Zahra, ${ }^{1}$ Nury Nusdwinuringtyas ${ }^{2}$

pISSN: 0853-1773 - elSSN: 2252-8083 https://doi.org/10.13181/mji.bc. 215477 Med J Indones. 2021;30:306-10

Received: April 27, 2021

Accepted: December 14, 2021

Authors' affiliations:

${ }^{1}$ Department of Physical Medicine and Rehabilitation, Faculty of Medicine, Universitas Indonesia, Universitas Indonesia Hospital, Depok, Indonesia, ${ }^{2}$ Faculty of Medicine, Universitas Indonesia, Jakarta, Indonesia

\section{Corresponding author:} Nury Nusdwinuringtyas Faculty of Medicine, Universitas Indonesia, Jalan Salemba Raya No. 6, Central Jakarta 10430, DKI Jakarta, Indonesia

Tel/Fax: +62-21-3160493

E-mail: nury_nus@yahoo.com

\begin{abstract}
BACKGROUND The recovery after prolonged immobilization during hospitalization because of COVID-19 is the primary goal of moderate to severe COVID-19 rehabilitation. Lower extremity muscle function assessment after immobilization is needed before starting mobilization. Hence, this study aimed to evaluate the feasibility of the modified 30-second sit-to-stand test (m30STS) as one of the prospective tools of functional capacity assessment in moderate COVID-19.
\end{abstract}

METHODS This cross-sectional study recruited the subjects consecutively. All eligible subjects with oxygen saturation $\left(\mathrm{SaO}_{2}\right) \geq 95 \%$ with or without oxygen supplementation performed the m30STS following the Bohannon's guidelines. The score of m30STS was calculated based on the number of stands completed within $30 \mathrm{sec}$. A higher score of the m30STS indicated better lower extremity function.

RESULTS Mean score of m30STS was 13.3. No subjects had oxygen desaturation or increased heart rate, and no fall incidents occurred.

CONCLUSIONS The m30STS is feasible and safe to evaluate lower extremity for moderate COVID-19 patients with $\mathrm{SaO}_{2}>95 \%$. The absence of oxygen desaturation and increase in heart rate showed no increased oxygen consumption during the test.

KEYWORDS COVID-19, functional capacity, modified 30-second sit-to-stand test
Complications after moderate to severe acute respiratory syndrome coronavirus 2 infection affect the cardiovascular and respiratory systems due to systemic inflammation from the prolonged immobilization. ${ }^{1}$ Lung volume reduction due to a sudden acute phase of proinflammatory cytokines results in multiorgan failure that increases the risk for acute respiratory distress syndrome, lung fibrosis, potentially prolonged immobilization, and eventual death. ${ }^{2-4}$

Functional capacity evaluation in moderate to severe coronavirus disease 2019 (COVID-19) patients after immobilization is essential due to the decreased body metabolism, including the cardiac muscle's ability to supply energy throughout the body. Decreased energy after immobilization deteriorates functional ability to perform daily activities. However, no studies have examined the functional capacity deterioration in COVID-19 patients.

The modified 30-second sit-to-stand test (m30STS) is one of the functional capacity tests that might be feasible for immobilized patients. ${ }^{5}$ Performing the m30STS is preferred because it is simple, can be performed on the bedside, does not cause fatigue, and 
requires a small space and short duration. Moreover, the m30STS is highly correlated with the 6-minutes walking test (6MWT) in evaluating physical fitness. ${ }^{6}$ In the clinical field, the m30STS is commonly used as an indicator of balance, strength, and proprioception, particularly in older patients with chronic disease and immobilized patients, and is highly correlated with cardiovascular fitness in the elderly. ${ }^{7}$ The ability to stand up from a sitting position independently is an important evaluation of the lower limb. ${ }^{8} \mathrm{~A}$ lower score of the m30STS indicates a lower cardiovascular fitness level and high fall and mortality risks. ${ }^{7}$ This study aimed to evaluate the feasibility of the m30STS in moderate COVID-19 patients in isolation ward to determine the out-of-bed mobilization.

\section{METHODS}

This was a cross-sectional study using consecutive sampling. This study was conducted in Universitas Indonesia Hospital from January to June 2021 and approved by the Ethics Committee of Universitas Indonesia Hospital (No: 0012/SKPE/KKO/2021/00). All participants were enrolled from the COVID-19 isolation ward. The inclusion criteria were moderate COVID-19 patients who had oxygen saturation $\left(\mathrm{SaO}_{2}\right) \geq 95 \%$ with or without oxygen supplementation and could ambulate with or without an assistive device. The exclusion criteria were uncontrolled blood pressure, paralysis of one or both legs, and the presence of cognitive impairment. Only participants with complete data and who signed the informed consent were included in this study.

\section{Modified 30-second sit-to-stand test (m30STS)}

The m30STS is commonly used in vulnerable populations to evaluate the functional strength of lower extremity muscles and balance. The m30STS score is calculated based on the number of stands completed within $30 \mathrm{sec}$. A lower score of the m30STS indicates decreased functional capacity of the lower extremity, which suggests poor mobilization.7 The test was conducted following Bohannon's 2012 guidelines using a standard chair (45 cm in height without armrests) or by sitting on the edge of the bed (Figure 1). The m30STS protocols allow hand support while standing.5,7,9

Before performing the m30STS, the participants were given a simple verbal instruction and visual demonstration by the examiner. The bed height was adjusted to the knee height of each participant, with both knees perpendicular to 90 degrees. ${ }^{7}$ The m30STS procedures were sitting with both feet on the floor, standing until the knees and hips were maximally extended with or without an assistive device, and going back to the sitting position.?

All subjects were allowed to use their hands during the test. The movements were repeated as quickly as possible within $30 \mathrm{sec}$, and the number of successful stands was recorded. ${ }^{10-13}$ The m30STS score was then classified according to the stratification in a healthy elderly population. ${ }^{13}$

The $\mathrm{SaO}_{2}$ and heart rate measurements were performed before and after the m30STS to ensure the patient's safety. The test was also supervised by two examiners to prevent unpredictable conditions during the m30STS. The test was discontinued if the participant had $\mathrm{SaO}_{2}<90 \%$ or decreased $\geq 2 \%$ compared with the previous measurement during the test. ${ }^{14}$ Participants with an increased heart rate of $>150$ times/min were considered in danger.

\section{Statistical analysis}

Data analysis was performed using SPSS software version 20.0 (IBM Corp., USA). The significance level
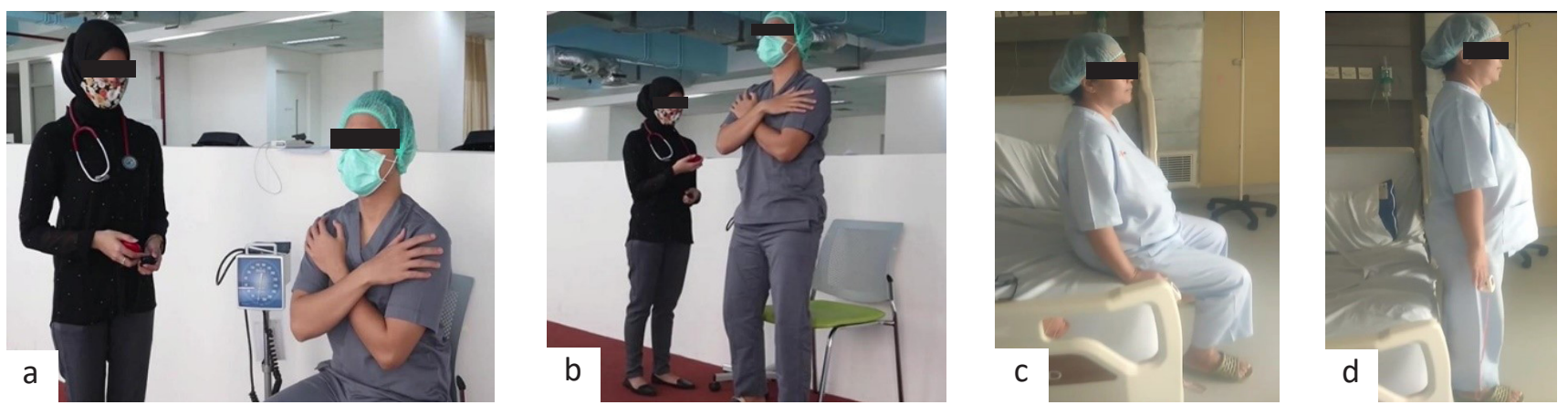

Figure 1. Modified 30-second sit-to-stand test (m30STS) according to Bohannon's guidelines. Sit-to-stand position using a standard chair ( $45 \mathrm{~cm}$ in height without armrests) ( $\mathrm{a} \& \mathrm{~b}$ ); sit-to-stand position on the edge of the bed (c \& d) 
was set at $p<0.05$ for all statistical analyses. KruskalWallis test and Spearman's correlation were used to examine the relationship between the m30STS and age, heart rate, $\mathrm{SaO}_{2}$, and length of stay. Mann-Whitney $U$ test was used to compare the m30STS among sex group.

\section{RESULTS}

Table 1 summarizes the demographic data for the eligible subjects. Of 110 participants, only 92 were included because 16 refused to participate, and 2 had lower extremity muscle paralysis. Table 1 shows that more than $60 \%$ of the participants were male (66\%). During the test, most participants used hand support while standing without any fall incidents. No participants showed oxygen desaturation after the test. The mean score of m30STS was 13.3 (4.76). Of 92

Table 1. Demographic and clinical data

\begin{tabular}{|c|c|}
\hline Variables & $N=92$ \\
\hline Age (years), mean (SD) & $47.0(12.36)$ \\
\hline$\leq 40, \mathrm{n}(\%)$ & $25(27)$ \\
\hline $41-60, \mathrm{n}(\%)$ & $57(62)$ \\
\hline$\geq 60, \mathrm{n}(\%)$ & $10(11)$ \\
\hline \multicolumn{2}{|l|}{ Sex, n (\%) } \\
\hline Male & $61(66)$ \\
\hline Female & $31(34)$ \\
\hline m30STS (times), mean (SD) & $13.3(4.76)$ \\
\hline $\mathrm{SaO}_{2}$ post-test (\%), mean (SD) & $96.8(1.29)$ \\
\hline$<95, \mathrm{n}(\%)$ & $3(3)$ \\
\hline $95-97, \mathrm{n}(\%)$ & $60(65)$ \\
\hline$\geq 98, \mathrm{n}(\%)$ & $29(32)$ \\
\hline \multicolumn{2}{|l|}{ Heart rate post-test (times/min) } \\
\hline$<60, \mathrm{n}(\%)$ & $1(1)$ \\
\hline Median & 57 \\
\hline $60-90, \mathrm{n}(\%)$ & $38(41)$ \\
\hline Median (min-max) & $82.3(80.1-84.5)$ \\
\hline $91-120, \mathrm{n}(\%)$ & $52(57)$ \\
\hline Median (min-max) & $99.0(95.8-102.5)$ \\
\hline $121, \mathrm{n}(\%)$ & $1(1)$ \\
\hline Length of stay (days), mean (SD) & $20.6(10.75)$ \\
\hline$\leq 10, \mathrm{n}(\%)$ & $9(10)$ \\
\hline $11-20, \mathrm{n}(\%)$ & $52(56)$ \\
\hline$>21, \mathrm{n}(\%)$ & 31 (34) \\
\hline
\end{tabular}

m30STS=modified 30-second sit-to-stand test; $\mathrm{SaO}_{2}=$ oxygen saturation; $\mathrm{SD}=$ standard deviation participants, $3(3 \%)$ had $\mathrm{SaO}_{2} 94 \%$, and 1 had a heart rate $>120$ times/min during the test.

Table 2 shows no significant differences between age, $\mathrm{SaO}_{2}$, heart rate, or length of stay and score of m30STS. Males had a higher m30STS score than females. However, there was a weak correlation between $\mathrm{SaO}_{2}$ and the m30STS score.

\section{DISCUSSION}

Physical capacity evaluation of COVID-19 patients in an inpatient ward requires an adequate and precise tool to assess functional capacity. ${ }^{1}$ Considering the patients' safety, we hindered desaturation and fatigue occurrences during the test to determine the timing of out-of-bed mobilization.7 Previous studies have shown that the m30STS is effective and safe to evaluate the functional strength of lower extremity muscles, particularly in immobilized patients. A higher score of the m30STS indicates a greater lower extremity strength. ${ }^{11,15}$ This test rarely causes fatigue because it only takes $30 \mathrm{sec}$ and is based on the patient's ability. ${ }^{10,16,17}$ Furthermore, the m30STS indirectly evaluates the cardiorespiratory fitness, evidenced by a moderate to strong positive correlation with the $6 \mathrm{MWT} .^{18}$ In addition, a higher score of m30STS also showed better cardiorespiratory fitness, which implies walking ability. 6,17,19

Our study showed that moderate COVID-19 patients had a lower score of m30STS, compared with the healthy elderly population.7,15 This was an interesting result as most subjects had a lower score of m30STS than the healthy elderly population, although not all COVID-19 patients were elderly (the score was 17-20). ${ }^{8,12}$ Elderly people are a special population due to age-related disability, degenerative disease, decreased overall metabolism, and high fall risks.5,7 Thus, age should become a safety consideration when initiating the out-of-bed mobilization in the COVID-19 isolation ward.

A low score of m30STS in patients with moderate COVID-19 patients indicates similar potential vulnerable conditions in physical function as in the healthy elderly. In the healthy elderly, a higher score of m30STS indicated better physical fitness, greater ability to perform the out-of-bed mobilization, especially walking, and could predict fall or recurrent fall incidence.5,10,11 Bohannon et $a^{5}$ found that elderly patients with a lower score of m30STS (less than five repetitions) indicated high fall or 
Table 2. Relationship between age, sex, $\mathrm{SaO}_{2}$, heart rate, and m30STS score

\begin{tabular}{|c|c|c|c|c|c|c|c|c|}
\hline \multirow{2}{*}{ Variables } & \multicolumn{5}{|c|}{ m30STS } & \multirow{2}{*}{$\frac{\text { Mean differences }}{p}$} & \multicolumn{2}{|c|}{ Correlation* } \\
\hline & $\leq 12, \mathrm{~N}$ & $13-15, \mathrm{~N}$ & $16-20, N$ & $\geq 21, \mathrm{~N}$ & Mean (SD) & & $r$ & $p$ \\
\hline Age (years) & & & & & & $0.368^{+}$ & -0.08 & \\
\hline$\leq 40$ & 9 & 9 & 5 & 2 & $14.36(0.709)$ & & & \\
\hline $41-60$ & 28 & 14 & 11 & 4 & $12.88(0.615)$ & & & \\
\hline$\geq 60$ & 5 & 3 & 1 & 1 & 13.4 (2.409) & & & \\
\hline Sex & & & & & & $0.047^{\ddagger}$ & - & \\
\hline Male & 23 & 17 & 14 & 7 & $14.44(0.64)$ & & & \\
\hline Female & 19 & 9 & 3 & 0 & $11.16(0.61)$ & & & \\
\hline $\mathrm{SaO}_{2}(\%)$ & & & & & & $0.533^{+}$ & 0.206 & 0.048 \\
\hline$<95$ & 3 & 0 & 0 & 0 & $11.00(0.57)$ & & & \\
\hline $95-97$ & 28 & 20 & 8 & 4 & $12.7(0.55)$ & & & \\
\hline$\geq 98$ & 11 & 6 & 9 & 3 & $14.9(1.04)$ & & & \\
\hline Heart rate (times/min) & & & & & & $0.368^{+}$ & 0.132 & 0.21 \\
\hline$<60$ & 1 & 0 & 0 & 0 & 8 & & & \\
\hline $60-90$ & 20 & 9 & 8 & 1 & $12.24(0.758)$ & & & \\
\hline $91-120$ & 20 & 17 & 9 & 6 & $14.27(0.656)$ & & & \\
\hline$>121$ & 1 & 0 & 0 & 0 & 12 & & & \\
\hline
\end{tabular}

m30STS=modified 30-second sit-to-stand test; $\mathrm{SaO}_{2}=$ oxygen saturation; SD=standard deviation

Statistical analysis was performed using *Spearman test; ${ }^{\dagger}$ Kruskal-Wallis test; ${ }^{\ddagger}$ Mann-Whitney $U$ test. A p-value of <0.05 was considered statistically significant

recurrent fall risks during the out-of-bed mobilization $(r=-0.30, p=0.03)$. However, all subjects in our study showed a good tolerance of the m30STS, characterized by the absence of desaturation state $\left(\mathrm{SaO}_{2}<90 \%\right)$, no increased heart rate exceeding the danger threshold (>150 times/min), and no fall incidence. Moving from sitting to standing requires a fair physical status. In general, relative immobilization causes decreased lower extremity strength capacity, weak coordination, and lower balance in elderly and other vulnerable populations. ${ }^{719}$ This result gives a good insight that the score of m30STS could be used as a safety indicator when initiating the out-of-bed mobilization.

Moreover, other results of this study were consistent with previous studies. First, the younger subjects had a higher score of m30STS than the older subjects. Second, men had a higher score of m30STS than women. This finding is correlated with the natural history of cardiovascular system deterioration and musculoskeletal strength and endurance, especially the lower extremity muscles, which are eventually easy to fatigue while performing daily activities. ${ }^{6,7,11,15,17,18}$ Males anatomically have a higher trunk rotation ability which results in a higher torsion for trunk movement for more flexibility, ease, and strength in hip flexion and extension. ${ }^{20}$

We did not face any significant difficulty during the test. Performing the bedside m30STS may be simpler than the 6MWT for COVID-19 patients treated in an isolation ward because it only requires a small space. Consistent with previous studies, we found that the m30STS is simple, easy, and safe for moderate COVID-19 patients who are initiating the out-of-bed mobilization activities, such as walking, in an isolation ward. .,10,11,19 We limited the subjects with $\mathrm{SaO}_{2}<94 \%$ to prevent the unpredictable states such as risk of falls and fear of mobilization due to eventual oxygen re-supplementation. In conclusion, the m30STS is a potential and safe tool for moderate COVID-19 patients with $\mathrm{SaO}_{2}>95 \%$ without desaturation when initiating the out-of-bed mobilization.

Conflict of Interest

The authors affirm no conflict of interest in this study.

\section{Acknowledgment}

We would like to acknowledge the staff in isolated ward and Physical and Medical Rehabilitation Unit of the Universitas Indonesia Hospital. 


\section{Funding Sources}

None.

\section{REFERENCES}

1. Salman D, Vishnubala D, Le Feuvre P, Beaney T, Korgaonkar J, Majeed A, et al. Returning to physical activity after covid-19. BMJ. 2021;372:m4721.

2. George PM, Barratt SL, Condliffe R, Desai SR, Devaraj A, Forrest I, et al. Respiratory follow-up of patients with COVID-19 pneumonia. Thorax. 2020;75:1009-16.

3. Mo X, Jian W, Su Z, Chen M, Peng H, Peng P, et al. Abnormal pulmonary function in COVID-19 patients at time of hospital discharge. Eur Respir J. 2020;55(6):2001217.

4. Ye Q, Wang B, Mao J. The pathogenesis and treatment of the 'cytokine storm' in COVID-19. J Infect. 2020;80(6):607-13.

5. Bohannon BR, Shove ME, Barreca SR, Masters LM, Sigouin CS. Five-repetition sit-to-stand test performance by communitydwelling adults: a preliminary investigation of times, determinants, and relationship with self-reported physical performance. Isokinet Exerc Sci. 2007;15(2):77-81.

6. Gurses HN, Zeren M, Denizoglu Kulli H, Durgut E. The relationship of sit-to-stand tests with 6-minute walk test in healthy young adults. Medicine. 2018;97(1):e9489.

7. McAllister LS, Palombaro KM. Modified 30-second sit-tostand test: reliability and validity in older adults unable to complete traditional sit-to-stand testing. J Geriatr Phys Ther. 2020;43(3):153-8.

8. Whitney SL, Wrisley DM, Marchetti GF, Gee MA, Redfern MS, Furman JM. Clinical measurement of sit-to-stand performance in people with balance disorders: validity of data for the fivetimes-sit-to-stand test. Phys Ther. 2005;85(10):1034-45.

9. Applebaum EV, Breton D, Feng ZW, Ta AT, Walsh K, Chassé K, et al. Modified 30-second sit to stand test predicts falls in a cohort of institutionalized older veterans. PLoS One. 2017;12(5):e0176946.

10. Yanagawa N, Shimomitsu T, Kawanishi M, Fukunaga T, Kanehisa H. Relationship between performances of 10-time-repeated sit-to-stand and maximal walking tests in non-disabled older women. J Physiol Anthropol. 2017;36(2).

11. Prastowo NA, Budiarta MO, Suryawinata K, Haryono IR. Comparing tools of balance tests in assessing balance of middle-aged women with or without exercises. JKKI. 2020;11(1):18-26.

12. Yang LL, Yang T. Pulmonary rehabilitation for patients with coronavirus disease 2019 (COVID-19). Chronic Dis Transl Med. 2020;6(2):79-86.

13. Centers for Disease Control and Prevention (CDC). Assessment 30-second chair stand 2017. Centers for Disease Control and Prevention (CDC). Available from: https://www.cdc.gov/steadi/ pdf/STEADI-Assessment-30Sec-508.pdf.

14. Rikli RE, Jones CJ. Functional fitness normative scores for community residing older adults, ages 60-94. J Aging Phys Act. 1999;7:162-81.

15. Misdalia T, Moeliono MA, Idjradinata P. The effect of loaded sitto-stand exercise with periodization in dimension $\mathrm{D}$ and $\mathrm{E}$ gross motor function measure spastic diplegic type of cerebral palsy. J Indon Med Assoc. 2012;62(10):397-401. Indonesian.

16. Vaidya T, Chambellan A, de Bisschop C. Sit-to-stand tests for COPD: a literature review. Respir Med. 2017;128:70-7.

17. Bui KL, Nyberg A, Maltais F, Saey D. Functional tests in chronic obstructive pulmonary disease, part 1: clinical relevance and links to the international classification of functioning, disability, and health. Ann Am Thorac Soc. 2017;14(5):778-84.

18. Meriem M, Cherif J, Toujani S, Ouahchi $Y$, Hmida AB, Beji M. Sit-to-stand test and 6-min walking test correlation in patients with chronic obstructive pulmonary disease. Ann Thorac Med. 2015;10(4):269-73.

19. Schurr K, Sherrington C, Wallbank G, Pamphlett P, Olivetti L. The minimum sit-to-stand height test: reliability, responsiveness and relationship to leg muscle strength. Clin Rehabil. 2012;26(7):65663.

20. Roldán-Jiménez C, Cuesta-Vargas Al, Bennett P. Assessing trunk flexo-extension during sit-to-stand test variant in male and female healthy subjects through inertial sensors. Phys Sportsmed. 2019;47(2):152-7. 